\title{
Frente ao Oráculo: Murilo Mendes escreve Siciliana
}

\author{
HorÁCIO COSTA
}

Universidade de São Paulo

\begin{abstract}
RESUMO: ANÁLISE DO LIVRO SICILIANA, DE MURILO MENDES, ESCRITO EM 1957-8, CONSIDERADO UM EXEMPLO DE DICÇÃO ELEVADA NA POESIA BRASILEIRA MODERNA, E QUE REVELA O ENCONTRO DO POETA COM TEMAS ATEMPORAIS, AUSPICIADO PELA EXPOSIÇÃO DO POETA EXPATRIADO À VELHA CULTURA MEDITERRÂNEA.
\end{abstract}

ABSTRACT: THIS ESSAY ANALYZES THE POETRY BOOK SICILIANA, WRITTEN BY MURILO MENDES IN 1957-8, HEREBY CONSIDERED AN EXEMPLE OF LOFTY POETIC DICTION IN THE CONTEXT OF THE BRAZILIAN POETRY OF THE MODERNISM. SICILIANA REVEALS THE POET'S ENCOUNTER WITH TIMELESS THEMES, DUE TO THE PERSONAL EXPOSITION OF THE EXPATRIATE MENDES TO THE OLD MEDITERRANEAN CULTURE.

PALAVRAS-CHAVE: MURILO MENDES - POESIA BRASILEIRA MODERNA - SICÍLIA - CIVILIZAÇÃO MEDITERRÂNEA.

KEYWORDS: MURILO MENDES - MODERN BRAZILIAN POETRY - SICILIA - MEDITERRANEAN CIVILIZATION 
icília, a ilha triangular, a Trinácria dos gregos antigos, tem representado um destino fabuloso para o imaginário de gerações e gerações de poetas nela não nascidos. Nas Metamorfoses, Ovídio descreveu o destino do pastor Ácis após ser morto pelo ciclope Polifemo, ciumento do amor que ele e a bela ninfa Galatéia entre si mantinham: após sua morte, o sangue de Ácis é transformado em um rio que corre pelas encostas do Etna. Muitos séculos depois, Dom Luís de Gôngora, possivelmente o poeta mais importante do barroco espanhol, recuperou esta lenda em um poema que Octavio Paz considera a sua jóia, "Fábula de Polifemo y Galatea" (1613). Para gerações de poetas, a Sicília sempre pareceu cheia de significado: por exemplo, Goethe, precursor de todos os poetas errantes modernos, disse em seu Italianische Reise ("Viagem à Itália", 1816-17) que "ver a Itália sem ter visto a Sicília não é ver a Itália em absoluto, pois a Sicília é a chave para tudo". Uma terra tão multifacetada geograficamente quanto culturalmente e na qual o 'Tempo parece se desvendar até tornar-se uma sensação tão intensa quanto qualquer um dos cinco sentidos, a Sicília possui um encanto muito particular: aquele de ser uma forma de imago mundi.

Murilo Mendes já era um nome muito respeitado na literatura brasileira quando foi convidado como professor visitante pela Universidade de Roma - La Sapienza nos anos cinqüenta e fez a sua jornada siciliana. Ele fora um dos mais importantes poetas da segunda geração modernista, surgida por volta de 1930. Como já tive a oportunidade de afirmar em algumas ocasiões, sua obra sumariza, com a de Carlos Drummond de Andrade, as mais notáveis qualidades dessa importante geração. Desde as suas estréias, seus poemas eram escritos com uma clareza de tom que se mesclava exemplarmente bem com um pulsar conversacional e que não evitava tratar de certos temas considerados demasiado elevados pela iconoclasta geração de vanguarda, anterior a eles. Os primeiros modernistas brasileiros que iniciaram o movimento de renovação da literatura com fanfarra em 1922 - o ano da Semana de Arte Moderna de São Paulo favoreceram escrever poemas curtos e bem-humorados, que objetivavam uma comunicação direta, maliciosa com o leitor. Sua dicção era franca e positiva, tão diferente daquela que dominou a poesia brasileira sob a égide dos movimentos Simbolista e Parnasiano durante o século XIX, quanto estava conectado com o espírito dos "-ismos" que, em todo o mundo, se sucediam um ao outro nas primeiras décadas do século passado. Por volta de 1930, contudo, tal crença notável nos tempos modernos e no Modernismo abriu caminho a uma ope- 
ração poética mais sutil, e concomitantemente menos orientada a semelhante positividade: justamente, aquela desenvolvida pela geração de Drummond de Andrade e Murilo Mendes, a primeira totalmente moderna que a nossa literatura teve. Assim, as crenças triunfantes em um "brave modern world" foram matizadas em um modo mais crítico e auto-crítico. A poesia de Murilo Mendes revela sua orientação religiosa e sua turbulência espiritual; a de Drummond inclui suas memórias de infância de filho de ex-fazendeiros. Estes eram dois vieses praticamente ignorados pelos primeiros modernistas, às vezes chamados "heróicos", que estavam mais preocupados com a fundação de uma cultura brasileira moderna do que com a elocução de matérias subjetivas. Drummond e Mendes puderam imprimir na dicção da poesia brasileira sua renovação dos horizontes poéticos dos primeiros modernistas sem trair seus muito consideráveis avanços formais ou seu quociente vanguardista, e sem rasurar o seu discurso fundacional. Isto é o que nos possibilita considerá-los centrais no processo da poesia brasileira contemporânea.

Mendes deixou o Brasil para ir a Itália em um momento em que o país estava sofrendo mudanças rápidas. Brasília estava sendo construída; as Artes eruditas, populares e aplicadas se misturavam para criar um sentido de identidade cultural nacional que mostrava urbi et urbi a vitória da vertente brasileira do modernismo. A poesia, por sua vez, experimentou ainda outra mudança, com a afirmação do movimento de poesia concreta de São Paulo, que novamente representou quão profunda era a herança dos primeiros vanguardistas. Os poetas concretos, particularmente os mais ativos entre eles, os irmãos Haroldo e Augusto de Campos e Décio Pignatari, transformaram em seu o dictum de Oswald de Andrade, o "pai fundador" do Modernismo, um escritor brilhante de manifestos ousados e influentes durante os anos vinte: criar no Brasil um novo tipo de mercadoria, a "poesia para exportação". Difundida a sua operação dentro e fora do país, inclusive entre os poetas mais antigos tais como os próprios Drummond e Mendes, os poetas mais jovens, contudo, nunca deixaram a terra natal por longos períodos de tempo. Assim, em uma cultura em que uma das características mais idiossincráticas tem sido historicamente a ausência de expatriados, a determinação de Murilo Mendes em viver e trabalhar no exterior chama até hoje a atenção.

A utopia política e intelectual de criação de uma nova cultura abaixo da linha do Equador, distante da Europa e sustentadora de sua própria hubris, tem raízes 
em nossos tempos coloniais, e está relacionada com a formação do Brasil como um Estado independente, unificado sob a monarquia local. Mantida ao longo do século XIX, e reforçada pelos modernistas, foi totalmente responsável pela sua vitória. Apesar disso, essa tendência "nobre" de nosso caráter tem tido alguns efeitos colaterais, como por exemplo um pendor ao egocentrismo, embora tal exclua um viés narcisístico, pois os brasileiros vêem o seu país e a sua cultura principalmente como um "problema". Ao analisar em termos freudianos a dificuldade que os brasileiros têm para lidar com a velha metrópole, e por conseguinte com a sua origem política, lingüística e cultural, o crítico português Eduardo Lourenço observou que o Brasil se vê como o seu próprio pai, a sua própria origem (LOURENÇO, 2001). Tudo isso é aqui exposto como uma sinalizações para o entendimento das condições, das dificuldades que atuam culturalmente sobre qualquer um - e talvez particularmente sobre um poeta que se expatrie, considerando o contexto cultural brasileiro.

Murilo Mendes se estabeleceu na Europa nos anos cinqüenta por duas vezes: a primeira vez em 1954-5, na França e na Bélgica, e a segunda em Roma em 1957, desta vez por um período que se estenderia até o fim de sua vida. Nascido em 1901 no Estado de Minas Gerais, ele morreu em Lisboa em 1975. Em suas décadas na Europa e particularmente em Roma, construiu um círculo de amigos considerável, entre poetas e artistas. ${ }^{1}$ Em 1972 , contando já com muitos livros seus publicados em italiano, ele ganhou o prêmio Etna-Taormina, o mais importante na Itália naquela época. A origem dessa premiação pode ser encontrada na publicação de Siciliana, seu primeiro livro "italiano", escrito em 1954-5 em um período como professor visitante à Universidade de Roma - La Sapienza, que lhe permitiu intensas viagens pelo país. Foi publicado primeiro em 1959 numa edição bilíngüe (traduzida por A. A. Chiocchi; Caltanissetta, Sicília, Editore Salvatore Sciascia), prefaciada por Giuseppe Ungaretti, quem fora o primeiro professor de literatura italiana na Universidade de São Paulo, um de seus amigos mais íntimos, e que se tornaria um seu tradutor (de Finestra del Caos - "Janela do Caos", Milão, Schweiler, 1961). Em resumo, Siciliana representou sua estréia em um cenário que logo

1 Um livro como Murilo Mendes: L'occhio del poeta (organizado por Luciana Stegagno Picchio. Roma: Gangemi Editore, 2001), que reúne seus escritos sobre artistas plásticos contemporâneos, em grande maioria referente a amigos seus, dá perfeita conta disso. 
se tornaria o seu; mais significativo do que isso, oferece um boa amostragem do poeta brasileiro no momento em que encara o "outro" do Velho Mundo num momento privilegiado em sua vida e carreira.

Naturalmente, Mendes já era um poeta cosmopolita antes de escrever este livro, e a parte de sua obra escrita antes de deixar o Brasil é cheia de referências, culturais e afetivas, ao arquivo da poesia e cultura ocidentais. Mas o que está em tela de juízo aqui não é simplesmente o cosmopolitismo, como um conceito aplicável a qualquer um que desenvolva uma orientação menos "nacional" para as bases de seu trabalho ou intervenção. Bem mais do que considerá-la simplesmente cosmopolita, pelo ranço semântico de mundanidade remanescente nessa expressão, o que sublinho aqui é que a escrita de Siciliana origina-se numa postura diferente, que se amalgama no encontro de uma certa subjetividade com um locus que possibilitou o seu exercício em nível ótimo. Essa questão não vem expressada simplesmente pelo tópico de um indivíduo representativo de uma cultura nova que se defronta com outra antiga; mais ainda, ela não pode ser relacionada ao bipolar e superestimado debate modernismo versus classicismo - ou América versus Europa -, no que tange aos temas que implica. De fato, no caso que estudamos, tal encontro implicou a escritura de uma coleção de treze poemas, com um tonus altamente consistente, sofisticado e escrutinador, e que se dirige a assuntos humanos fundamentais.

Siciliana expressa assuntos tais como o significado do tempo e a existência do oráculo, a busca por uma voz poética autônoma como uma ferramenta para a sua exposição; ainda, embasa-se na premissa da existência da percepção-guia da voz do Ser, oculto ela e oculto ele, que ecoa em alguns lugares e momentos particulares. Todos estes assuntos coincidem com a leitura da Sicília em si. A toponímia siciliana é claramente manifestada: cada um dos poemas corresponde a uma certa cidade ou monumento. Alguns deles, como o primeiro - "Atmosfera siciliana" - trata da vida siciliana no presente contrastada com a persistência das sombras da história que nela incidem. A idéia de drama - sexo, violência, éclat - está presente nesses poemas. Outra série trata de uma Sicília quintessencial: um lugar onde os restos de eras antigas, as ruínas, facilitam o encontro do poeta não com o passado como evocação mas com, por assim dizer, com a caracterização de passado presente. Ao invés de drama, estes poemas indiretamente relacionados com a vida siciliana atual focalizam a tragédia. Eu os privilegiarei na análise que segue. 
Ao confrontar esta sensação em um poema chamado "Meditação em Agrigento", e após usar a palavra "oráculo" em um poema anterior ("O Templo de Segesta"), Murilo escreve "Transformar-se ou não, eis o problema", parafraseando a elocução de Hamlet. Isto recupera um de seus versos - do "Pós-Poema", incluído em Poesia Liberdade, 1945 - que diz "Não se trata de ser ou não ser, / Trata-se de ser e não ser". Em resumo, nos versos citados, o Ser é visto como transformacional: a dúvida ontológica, o verso metafísico shakespeariano é reformado para não mais ser relacionado ao essencial, mas sim ao transitório. E uma ontologia transitória não seria, realmente, uma contradição em termos? No seguinte poema da série, "Canção de Términi Imerese", o enigma parece resolver-se: "Transformei-me à minha imagem, / e o mesmo oráculo sou". Aparte do conceito quase blasfemo, se o enunciado for considerado em relação à tradição judaico-cristã do Gênesis, o que Murilo dá entender nesses versos é que a poesia - ou melhor dito, a palavra poética - pode ser o acesso à sua própria transformação como ser humano individual uma vez contactado através dela, um oráculo seu próprio. Em "O Eco em Siracusa", o poeta arrisca ainda uma outra fórmula, também ligada ao oracular e à especificidade da palavra poética: para "tocar o mundo com a voz". A estrofe abaixo em questão reza:

Nas tuas cavernas oblongas

Há um deus que se levanta,

Reconstituído no eco:

Toquemos o mundo com a voz. (MENDES, 1994: 573)

De qualquer modo, voz de quem? A nossa própria, ou a do eco, ou a do seu eco? Ou aquele do eco de "deus que se levanta"? O poeta não diz "Toquemos o mundo com nossa voz", mas de um modo evasivo, "com a voz". Tais disquisições podem soar artificiosas. Contudo, a grandeza aparece naturalmente: nem grandiloqüência, nem retórica artificial. Sim, imprecisão: provavelmente necessária. O eco contrapõe-se ao oráculo, mencionado em "Canção de Términi Imerese": tocar o mundo com a palavra do oráculo ou a do seu eco? E no caso do oráculo ser próprio, com a própria palavra ascendida, assim, a palavra poética. Quero crer que sim: esta "voz", este dizer, não parece desligar-se nem do oracular nem do quintessencialmente poético. $\mathrm{Na}$ última estrofe de "O eco em Siracusa” - a propósito, o último poema de Siciliana -, Murilo Mendes diz: 
Áspera voz, duplo eco

Habitado pelo deus

Que subsiste ainda

No homem inumano

Eco. (Ibidem)

Mas novamente, a sintaxe truncada não deixa isso claro: é a "áspera voz" ou é o Homem ou quem o poeta chama de eco inumano, habitado pelo deus ainda subsistente, de quem soa o "duplo eco"? Uma vez mais, tal deus não é referido, como em alguns outros poemas da coletânea, em letra maiúscula. Talvez nós sejamos o eco inumano de um deus menor, que "ministra oráculos espessos", como outro verso deste mesmo poema evidencia.

"O eco em Siracusa" pode ter sido inspirado pelo antigo monumento siracusano, L’Orecchio di Dionigi, o "Ouvido de Dionísio". O nome refere-se a uma particularidade que se encontra em uma caverna artificial batizado por Caravaggio (1571-1610) durante a sua jornada ou fuga siciliana, dois mil anos depois de ter sido escavada sob o reino do tirano Dionísio de Siracusa (séc. V A. C.). O tirano ouvia as conspirações de seus inimigos através de um conduto escondido, que comunica a caverna, onde ficavam os prisioneiros, com a superfície, onde ele se situava, e que o celebrado pintor comparou a um ouvido. Se esta suposição for verdadeira, como se pode ponderar, Murilo parte de um espaço específico mas quase que o rasura, transformando-os em uma espécie de poesia incaracterística, não-anedótica ou circunstancial, embora ainda relacionada à história siciliana; ainda assim, no caso dessa suposição ser positiva, a sua aproximação ao turístico “Ouvido de Dionísio" é absolutamente não-folclórica.

Em dois poemas escritos em documentos do período da Magna Grécia, Murilo faz declarações ousadas. Em "As ruínas de Selinunte", diz "para a catástrofe, em busca/ da sobrevivência, nascemos". Em "Elegia de Taormina", escrita nas ruínas do famoso anfiteatro grego, ele exclama:

Ó intolerável beleza,

Ó pérfido diamante,

Ninguém, depois da iniciação, dura

No teu centro de luzes contrárias. (MENDES, 1994: 569) 
Catástrofe como destino; beleza como tragédia; beleza e morte; dor e êxtase. Estes são topoi afins do Barroco, no reino das Artes, ou da Escatologia, no da Religião. Nessa última estrofe, o poeta reivindica indiretamente ter experimentado algum tipo de iniciação. Devemos examinar sua poesia para identificar o momento quando esse fato primeiro entra em sua poética. Já no Rio de Janeiro, nos anos 1920, em um memorável poema chamado "Mapa" (publicado em Poemas, 1930), o sentimento é, justamente, de “iniciação". Em Siciliana o tonus é precisamente este, e a noção de ser iniciado novamente pode responder à ousadia da dicção, à intrepidez frente ao grandioso, e à escrita de um poesia como uma ferramenta para questionar o oracular, todos traços que de meu ponto de vista caracterizam a coletânea.

É minha idéia que a Sicília foi o catalisador de um dos mais importantes livros da poesia contemporânea brasileira.

\section{Referências Bibliográficas}

LOURENÇO, Eduardo. A nau de Ícaro. São Paulo: Companhia das Letras, 2001. MENDES, Murilo. Poesia completa e prosa. Rio de Janeiro: Nova Aguilar, 1994. PICCHIO, Luciana Stegagno (org.). Murilo Mendes: L occhio del poeta. Roma: Gangemi Editore, 2001. 